\title{
Outcome measures in older persons with acquired joint contractures: a systematic review and content analysis using the ICF (International Classification of Functioning, Disability and Health) as a reference
}

\author{
Gabriele Bartoszek ${ }^{1,2}$, Uli Fischer ${ }^{3}$, Martin Müller ${ }^{3,4}$, Ralf Strobl ${ }^{3,4}$, Eva Grill ${ }^{3,4}$, Stephan Nadolny ${ }^{1}$
} and Gabriele Meyer ${ }^{1,2^{*}}$

\begin{abstract}
Background: Joint contractures are a common health problem in older persons with significant impact on activities of daily living. We aimed to retrieve outcome measures applied in studies on older persons with joint contractures and to identify and categorise the concepts contained in these outcome measures using the ICF (International Classification of Functioning, Disability and Health) as a reference.

Methods: Electronic searches of Medline, EMBASE, CINAHL, Pedro and the Cochrane Library were conducted $(1 / 2002-8 / 2012)$. We included studies in the geriatric rehabilitation and nursing home settings with participants aged $\geq 65$ years and with acquired joint contractures. Two independent reviewers extracted the outcome measures and transferred them to concepts using predefined conceptual frameworks. Concepts were subsequently linked to the ICF categories.

Results: From the 1057 abstracts retrieved, 60 studies met the inclusion criteria. We identified 52 single outcome measures and 24 standardised assessment instruments. A total of 1353 concepts were revealed from the outcome measures; $96.2 \%$ could be linked to 50 ICF categories in the 2nd level; $3.8 \%$ were not categorised. Fourteen of the 50 categories (28\%) belonged to the component Body Functions, 4 (8 \%) to the component Body Structures, 26 (52 \%) to the component Activities and Participation, and 6 (12\%) to the component Environmental Factors.
\end{abstract}

Conclusions: The ICF is a valuable reference for identifying and quantifying the concepts of outcome measures on joint contractures in older people. The revealed ICF categories remain to be validated in populations with joint contractures in terms of clinical relevance and personal impact.

Keywords: Joint contracture, Aged, Outcome, Assessment, Geriatric rehabilitation, Nursing homes

\footnotetext{
* Correspondence: Gabriele.Meyer@medizin.uni-halle.de

${ }^{1}$ Faculty of Health, School of Nursing Science, Witten/Herdecke University,

Witten, Germany

${ }^{2}$ Institute for Health and Nursing Science, Martin Luther University,

Halle-Wittenberg, Germany

Full list of author information is available at the end of the article
}

\section{$\int$ Biomed Central}

(c) 2016 Bartoszek et al. Open Access This article is distributed under the terms of the Creative Commons Attribution 4.0 International License (http://creativecommons.org/licenses/by/4.0/), which permits unrestricted use, distribution, and reproduction in any medium, provided you give appropriate credit to the original author(s) and the source, provide a link to the Creative Commons license, and indicate if changes were made. The Creative Commons Public Domain Dedication waiver (http://creativecommons.org/publicdomain/zero/1.0/) applies to the data made available in this article, unless otherwise stated. 


\section{Background}

Joint contractures are characterised by a lack of full range of motion (ROM) of a joint and go along with deformity, disuse and pain. Joint contractures in upper limbs may result in inability to dress or eat independently, while contractures in lower limbs may cause instability, inability to walk and higher risk of bed confinement [1-3]. Joint contractures are recognised in the geriatric community as a disabling complication by frail older persons, particularly in residents of nursing homes [3-5]. International studies indicate a prevalence of joint contractures in older persons ranging between $20 \%$ and $80 \%$ [6-8]. This wide variation is due to heterogeneous definitions of joint contracture, different diagnostic criteria and data collection methods, different settings, sample sizes and participants' characteristics $[1,9]$.

In clinical settings, joint contractures are usually assessed by measuring the range of motion [10]. A variety of other functional measures is currently used for the assessment and evaluation of geriatric patients [10]. However, the impact of contractures on functioning, quality of life, and the ability to participate in everyday life seem to be assessed less often.

The International Classification of Functioning, Disability, and Health (ICF) [11] provides a useful framework for health outcome measurement in older persons [12]. The ICF can be understood as the operationalization of health and represents the outcome of the interaction between a person's health condition and his/her contextual factors [13]. The ICF is divided into two parts, with two components each. Part 1 covers Functioning and Disability and includes the components Body Functions (b) and Body Structures (s) as well as Activities and Participation (d). Part 2 covers Contextual Factors and contains the components Environmental Factors (e) and Personal Factors (pf) [11]. The review presented herein is a part of a broader project [14] aimed at deriving a standard set according to the methods recommended by the WHO for ICF Core Set development $[13,15]$.

The aims of our review were 1) to retrieve outcome measures applied in studies focusing on older persons with acquired joint contractures and 2) to identify and categorise the concepts contained in these outcome measures using the ICF as a reference.

\section{Methods}

\section{Literature search and study selection}

A systematic literature search was conducted in the following databases: Medline via PubMed, EMBASE, CINAHL, Pedro and the Cochrane Library. We included studies that had been carried out in geriatric rehabilitation hospitals or nursing homes. Participants had to be 65 years or older and to have acquired joint contractures. Studies dealing with congenital or genetic joint contractures were excluded. Three groups of search terms were combined (text words and MeSH terms, if available): 1) contracture, joint contracture; 2) elderly, old people, age, geriatric; and 3) geriatric care and nursing home. The search was limited to papers in German and English published between January 2002 and August 2012. The time limitation was applied since we aimed to identify outcome measures that are used in contemporary research [13]. The search strategy for PubMed is displayed in Table 1.

Since we wanted to draw a comprehensive picture of the content of outcome measures used in studies focusing on joint contracture outcomes in older persons, we decided to include randomised controlled trials, as well as controlled clinical trials, cohort studies, crosssectional studies and case-control studies.

The titles and abstracts of citations retrieved were screened and eligible full text articles were assessed by two independent reviewers. Results were compared and disagreement solved by discussion. A third reviewer was consulted when required.

\section{Data extraction and ICF linking procedure}

In a first step, the two reviewers extracted the outcome measures applied in the studies and the descriptive study characteristics, using a standardised electronic form. We included both standardised assessment instruments, like the Knee Society Score [16], and single outcome measures, such as joint range of motion measurement and specific clinical tests such as $\mathrm{x}$-ray. Assessment instruments were data extracted on the item level [13]. If the assessment was just mentioned but not described in detail in the retrieved study, we obtained it by reference checking, searching in books on clinical measures, and through internet search [17].

In a second step, the concepts that are contained in the assessment instrument items and single outcome measures were extracted [13]. For example, the item "heavy household duties" of the Western Ontario McMaster University Osteoarthritis Index [18] was conceptualized as "housework".

In a third step, the concepts of the outcome measures were linked to the ICF categories using established linking rules by trained researchers $[13,19]$. For example, the concept "housework" corresponds with the ICF category "Doing housework" (d640)". Personal Factors are not covered by the ICF and could therefore not be linked, e.g. concepts on patient satisfaction or coping [13].

Table 1 Complete search strategy - PubMed

((("Contracture" [Mesh] OR "joint contracture* ") AND (elderly OR geriatric OR aged OR "older person*" OR "old people") NOT dupuytren) NOT (Meta-Analysis[ptyp] OR Review [ptyp] OR Case Reports [ptyp]))) Filters: published in the last 10 years; English; German. 
If a concept was judged as too general to allow a decision on the linking to a specific ICF chapter, domain or category, the concept was considered as "not defined" [19], e.g. "any activity". At every step, the two independent reviewers (authors GB, SN) compared their results. Initial disagreement was solved by consensus. If there was no consensus, a third researcher (UF) was consulted. For quality assurance purposes, the reviewers attended a two-day training course provided by a senior ICF expert (MM) in preparation for the linking procedure. The senior expert supervised the entire process.

\section{Data analysis}

Absolute and relative frequencies of the standardised outcome assessment instruments and single outcomes were calculated. Only assessment instruments and single outcome measures used in at least two different studies are reported in this manuscript.

Relative frequencies of ICF categories and $95 \%$ confidence intervals were calculated. An ICF category that emerged more than once in a publication was counted only one time [13].

Only ICF categories referring to concepts measured in more than $5 \%$ of the studies are reported in this manuscript. The structure of the ICF is displayed in the
Additional file 1: The four major components (Body Functions, Body Structures, Activity and Participation, Environmental Factors) each have a number of subclassifications, called Chapters (first level), which again are sub-classified in Categories (second level). Each second-level category has sub-categories (third level), which in turn have sub-categories (fourth level). The example at the bottom of the chart shows the levels, into which Chapter b2 (Body Functions) is divided.

ICF categories are here presented at the 2nd level. If a concept had been linked to a 3rd or 4th level ICF category, i.e. a level with more detail, the corresponding 2nd level category is reported. Due to the hierarchical structure of the ICF and its codes, a category of a higher level of detail can be transferred to the category with a lower level of detail by deleting the appropriate number of digits of the ICF code (e.g. the $3^{\text {rd }}$ level category "Manipulating" (d4402) can be transferred to the $2^{\text {nd }}$ level category "Fine hand use" (d440)).

\section{Results}

Initially, a total of 1057 publications were identified; $n=60$ met the inclusion criteria and were included in the review. Figure 1 displays the flow of the literature search.

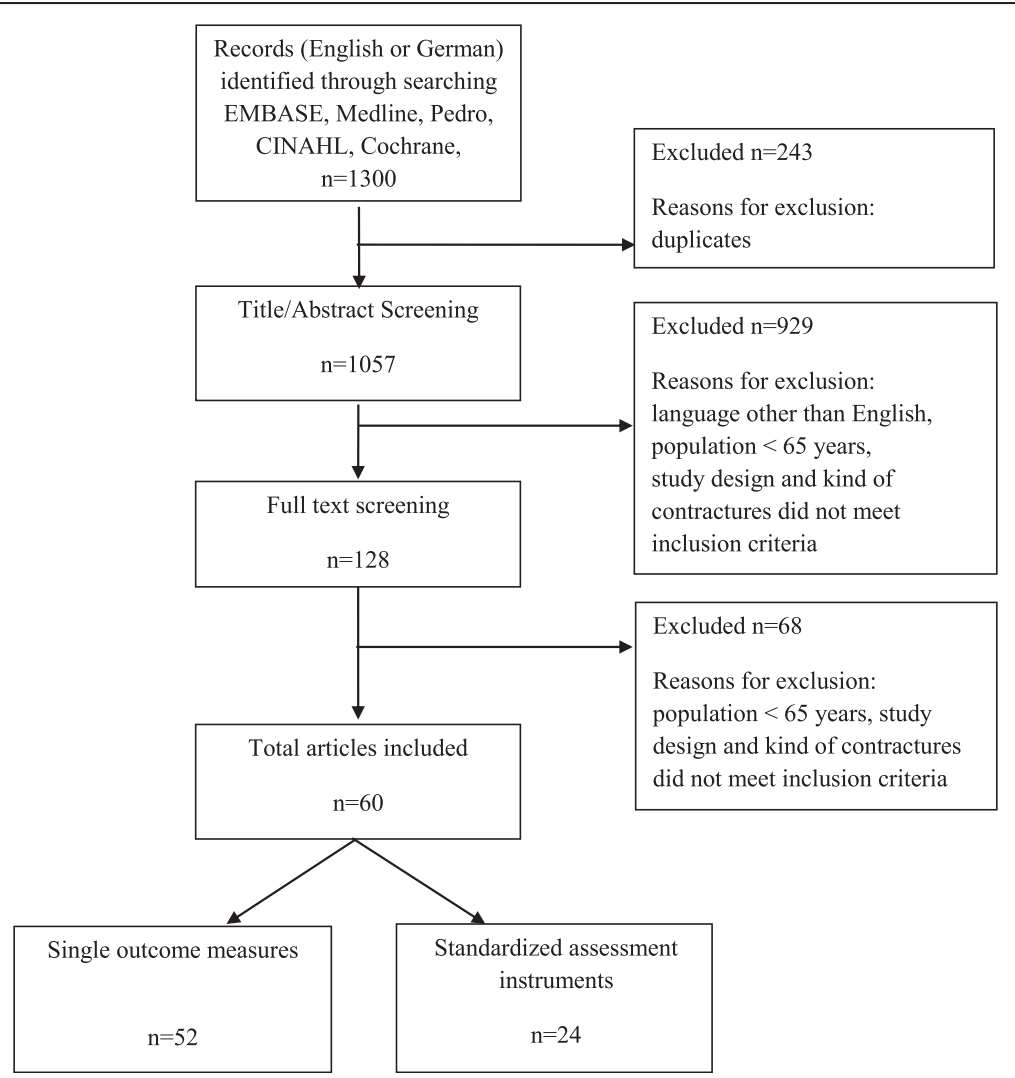

Fig. 1 Flow chart showing the search process and the inclusion of studies in the review 
The majority of included publications $(n=52,87 \%)$ were authored by medical scientists and physiotherapists, $n=6$ (10 \%) focussed on the acute and post-acute setting. Study participants suffered predominately from musculoskeletal $(n=51,85 \%)$ or neurological diseases $(n=7,12 \%)$. A total of 55 studies dealt with an intervention, either invasive (surgery or injections: $n=32$ ), non-invasive ( $n=20$, e.g. splint, exercise programmes) or both invasive and non-invasive interventions $(n=3$, e.g. injections as preparation for a stretching programme). The remaining five studies featured diagnostic procedures. Two studies $[5,6]$ addressed the nursing home setting and either estimated the prevalence of major joint contractures by a proxy assessment for persons with cognitive impairment [5] or measured the effect of a restorative care approach on the prevention of joint contractures [6].

The included studies covered a range of study designs, i.e. randomised controlled trials $(n=12)$, controlled clinical trials $(n=2)$, cross-sectional studies $(n=29)$, and cohort studies $(n=17)$.

In total, we identified 24 standardised assessment instruments and 52 single outcome measures. Table 2 displays the standardised outcome assessment instruments and Table 3 the single outcome measures that were reported in at least two different studies $(n=12$ and $n=19$, respectively). Throughout the 60 studies the most often used standardised assessment instruments were the Knee Society Score (KSS, $n=21$ ) [16], followed by the Hospital for Special Surgery Score (HSS, $n=8$ ) [20], the 3D Gait analysis $(n=5)$ [21], the Western Ontario McMaster University Osteoarthritis Index Scales (WOMAC, $n=4$ ) [18], and the Motor Assessment Scale

Table 2 Standardized outcome assessment instruments used in the 60 studies included

\begin{tabular}{ll}
\hline Outcome assessment instrument $^{\mathrm{a}}$ & No. (\%) \\
\hline Knee Society Score [19] & $21(35)$ \\
Hospital for Special Surgery Score [20] & $8(13)$ \\
3D Gait analysis [21] & $5(8)$ \\
Western Ontario McMaster University Osteoarthritis & $4(7)$ \\
Index Scales [18] & \\
Motor Assessment Scale [22] & $4(7)$ \\
Barthel Index [28] & 3 (5) \\
The Action Research Arm Test [29] & $2(3)$ \\
Tardieu Scale [30] & 2 (3) \\
Short Form Health Survey, SF-12 [31] & $2(3)$ \\
Modified Ashworth Scale [32] & 2 (3) \\
Mayo Elbow Performance Index [33] & $2(3)$ \\
Disabilities of the Arm, Shoulder and Hand [34] & $2(3)$ \\
\hline
\end{tabular}

${ }^{a}$ Only instruments that were used in at least two different studies are displayed

Values are absolute numbers (percentages)
Table 3 Single outcomes used in the 60 studies included

\begin{tabular}{ll}
\hline Measurement $^{\text {a }}$ & No. (\%) \\
\hline Range of motion (knee) & $34(57)$ \\
X-ray (knee) & $19(32)$ \\
Pain score (knee) & $10(17)$ \\
Subjects were asked to first stand and then & $5(8)$ \\
walk along a 10 m walkway & \\
Range of motion (shoulder) & $5(8)$ \\
Pain score (shoulder) & $5(8)$ \\
Stability of joint function (stabilometry) & $4(7)$ \\
Pain score (upper limb) & $4(7)$ \\
Hand grip strength & $3(5)$ \\
Range of motion (hip) & $3(5)$ \\
Strength of the knee extensors & $3(5)$ \\
Chair rise test & $2(3)$ \\
Muscle power (shoulder) & $2(3)$ \\
Range of motion (ankle) & $2(3)$ \\
Range of motion (finger/wrist) & $2(3)$ \\
Range of motion (lower limb, matching task) & $2(3)$ \\
X-ray (elbow) & $2(3)$ \\
X-ray (hip) & $2(3)$ \\
X-ray (shoulder) & $2(3)$ \\
\hline
\end{tabular}

${ }^{a}$ Only single outcomes that were used in at least two different studies are displayed

Values are absolute numbers (percentages)

(MAS, $n=4$ ) [22]. All other standardised assessment instruments identified were applied in $5 \%$ or less of the included studies. The five most often reported single outcome measures throughout the 60 studies were range of motion of the knee $(n=34)$, x-ray examination of the knee $(n=19)$, and pain score for the knee $(n=10)$, followed by pain score for the shoulder $(n=5)$ and range of motion of the shoulder $(n=5)$.

A total of 1353 concepts were revealed from the outcome measures. We were able to link $96.2 \%$ of these concepts to ICF categories; $2.5 \%(n=34$ concepts) were considered as "not defined" and $1.3 \%(n=18)$ as Personal Factors. The concepts were linked to 155 ICF categories. Five ICF categories $(3.2 \%)$ were linked to the 1st level of the ICF, $n=52(33.5 \%)$ to 2 nd level ICF categories, $n=88(56.8 \%)$ to 3rd level ICF categories and $n=10(6.5 \%)$ to 4th level ICF categories. The Tables 4, 5, 6 and 7 display the 2nd level ICF categories $(n=50)$ derived from the concepts of the standardised outcome assessment instruments and single outcomes. There were five ICF categories which were represented most frequently ( $>50 \%$ of the studies) and 21 ICF categories frequently ( $>10 \%$ of the studies). Two of the five ICF categories are part of the component Body 
Table 4 Relative frequency of 2nd level ICF categories. Component body functions (b)

\begin{tabular}{|c|c|}
\hline ICF code & ICF category \\
\hline & ICF chapter mental function \\
\hline b134 & Sleep functions \\
\hline b152 & Emotional functions \\
\hline \multirow[t]{2}{*}{ b235 } & Vestibular functions \\
\hline & ICF Chapter Sensory Function and Pain \\
\hline \multirow[t]{2}{*}{ b280 } & Sensation of pain \\
\hline & $\begin{array}{l}\text { ICF Chapter Function of Digestive, } \\
\text { Metabolic and Endocrine Systems }\end{array}$ \\
\hline \multirow[t]{2}{*}{ b525 } & Defecation functions \\
\hline & $\begin{array}{l}\text { ICF Chapter Genitourinary and } \\
\text { Reproductive Function }\end{array}$ \\
\hline \multirow[t]{2}{*}{ b620 } & Urination functions \\
\hline & $\begin{array}{l}\text { ICF Chapter Neuromusculoskeletal and } \\
\text { Movement-related Function }\end{array}$ \\
\hline b710 & Mobility of joint functions \\
\hline b715 & Stability of joint functions \\
\hline b720 & Mobility of bone functions \\
\hline b730 & Muscle power functions \\
\hline b735 & Muscle tone functions \\
\hline b755 & $\begin{array}{l}\text { Involuntary movement reaction } \\
\text { functions }\end{array}$ \\
\hline b770 & Gait pattern functions \\
\hline b780 & $\begin{array}{l}\text { Sensations related to muscles and } \\
\text { movement functions }\end{array}$ \\
\hline
\end{tabular}
$\%(95 \% \mathrm{Cl})$

Values are percentages $(95 \% \mathrm{Cl})$; the denominator is the number of studies included $(n=60)$. ICF categories referring to concepts measured in more than $5 \%$ of the studies are reported

Functions (Table 4): "Mobility of joint functions" (b710) (represented in $98 \%$ of included studies) and "Sensation of pain" (b280) (70 \%). The other three ICF categories most frequently represented were "Structure of lower extremity" (s750) (72\%) belonging to the component Body Structures (Table 5), "Walking" (d450) (65\%) and "Moving around" (d455) (53 \%) from the component Activities and Participation (Table 6). Six Environmental

Table 5 Relative frequency of 2nd level ICF categories.

Component body structures (s)

\begin{tabular}{lll}
\hline ICF code & ICF category & $\%(95 \% \mathrm{Cl})$ \\
& ICF chapter structure related to movement \\
\hline s720 & Structure of shoulder region & $13(5.9$ to 24.6$)$ \\
s730 & Structure of upper extremity & $22(12.1$ to 34.2$)$ \\
s740 & Structure of pelvic region & $8(2.8$ to 18.4) \\
s750 & Structure of lower extremity & $72(58.6$ to 82.5$)$ \\
\hline
\end{tabular}

Values are percentages $(95 \% \mathrm{Cl})$; the denominator is the number of studies included $(n=60)$. ICF categories referring to concepts measured in more than $5 \%$ of the studies are reported
Table 6 Relative frequency of 2nd level ICF categories. Component activities and participation (d)

\begin{tabular}{|c|c|c|}
\hline ICF code & ICF category & $\%(95 \% \mathrm{Cl})$ \\
\hline & ICF chapter general tasks and demands & \\
\hline \multirow[t]{2}{*}{$d 230$} & Carrying out daily routine & 7 (1.8 to 16.2$)$ \\
\hline & ICF Chapter Mobility & \\
\hline$d 410$ & Changing basic body position & 30 (18.8 to 43.2$)$ \\
\hline d415 & Maintaining a body position & 17 (8.3 to 28.5$)$ \\
\hline d420 & Transferring oneself & 22 (12.1 to 34.2$)$ \\
\hline d430 & Lifting and carrying objects & 8 (2.8 to 18.4$)$ \\
\hline d440 & Fine hand use & 13 (5.9 to 24.6$)$ \\
\hline d445 & Hand and arm use & $18(9.5$ to 30.4$)$ \\
\hline d450 & Walking & 65 (51.6 to 76.9$)$ \\
\hline d455 & Moving around & 53 (40 to 66.3 ) \\
\hline d465 & Moving around using equipment & 8 (2.8 to 18.4$)$ \\
\hline$d 470$ & Using transportation & 13 (5.9 to 24.6$)$ \\
\hline \multirow[t]{2}{*}{ d475 } & Driving & $8(2.8$ to 18.4$)$ \\
\hline & ICF Chapter Self-care & \\
\hline d510 & Washing oneself & 20 (10.8 to 32.3$)$ \\
\hline d520 & Caring for body parts & 10 (3.8 to 20.5$)$ \\
\hline d530 & Toileting & 15 (7.1 to 26.6$)$ \\
\hline d540 & Dressing & 20 (10.8 to 32.3$)$ \\
\hline d550 & Eating & 12 (4.8 to 22.6$)$ \\
\hline d560 & Drinking & 5 (1 to 13.9$)$ \\
\hline \multirow[t]{2}{*}{ d570 } & Looking after one's health & 7 (1.8 to 16.2$)$ \\
\hline & ICF Chapter Domestic Life & \\
\hline d620 & Acquisition of goods and services & $8(2.8$ to 18.4$)$ \\
\hline d640 & Doing housework & $13(5.9$ to 24.6$)$ \\
\hline d650 & Caring for household objects & 7 (1.8 to 16.2$)$ \\
\hline
\end{tabular}

ICF Chapter Interpersonal Interactions and Relationships

$d 770$

Intimate relationships

7 (1.8 to 16.2$)$

ICF Chapter Major Life Areas

d850 Remunerative employment

7 (1.8 to 16.2$)$

ICF Chapter Community, Social and Civic life

d920 Recreation and leisure

$12(4.8$ to 22.6$)$

d930

Religion and spirituality

7 (1.8 to 16.2$)$

Values are percentages $(95 \% \mathrm{Cl})$; the denominator is the number of studies included $(n=60)$. ICF categories referring to concepts measured in more than $5 \%$ of the studies are reported

Factors were categorised (Table 7), two of them "Products and technology for personal indoor and outdoor mobility and transportation" (e120) (45 \%) and "Design, construction and building products and technology of buildings for private use" (e155) (37 \%) - were frequently represented ICF categories. 
Table 7 Relative frequency of 2nd level ICF categories. Environment (e)

\begin{tabular}{|c|c|c|}
\hline ICF code & ICF category & $\%(95 \% \mathrm{Cl})$ \\
\hline & ICF Chapter Support and Relationships & \\
\hline e310 & Immediate family & 7 (1.8 to 16.2$)$ \\
\hline e315 & Extended family & 7 (1.8 to 16.2$)$ \\
\hline e320 & Friends & 7 (1.8 to 16.2$)$ \\
\hline \multirow[t]{2}{*}{ e399 } & Support and relationships, unspecified & 20 (10.8 to 32.3$)$ \\
\hline & ICF Chapter Products and Technology & \\
\hline e120 & $\begin{array}{l}\text { Products and technology for personal } \\
\text { indoor and outdoor mobility and } \\
\text { transportation }\end{array}$ & 45 (32.1 to 58.4) \\
\hline e155 & $\begin{array}{l}\text { Design, construction and building } \\
\text { products and technology of buildings } \\
\text { for private use }\end{array}$ & $37(24.6$ to 50.1$)$ \\
\hline
\end{tabular}

Values are percentages $(95 \% \mathrm{Cl})$; the denominator is the number of studies included $(n=60)$. ICF categories referring to concepts measured in more than $5 \%$ of the studies are reported

\section{Discussion}

This systematic review provides a detailed analysis of the content of outcome measures used in research dealing with joint contractures in older persons. We analysed 60 publications reporting on 52 single outcome measures and 24 standard assessment instruments revealing 1353 concepts. These concepts were linked to 50 2nd level ICF categories.

The most often linked categories emerged from the three assessment instruments KSS, HSS and WOMAC. These are used predominately in surgical and orthopedic evaluation [23, 24], but they address limitations in activities of daily living insufficiently and do not even address social participation.

Even though a relevant number of ICF categories $(n=26)$ belong to the component Activities and Participation, the chapter "Mobility" $(n=12)$ and "Self-care" $(n=7)$ are dominant and other limitations experienced by persons affected by joint contractures are not addressed [25], e.g. "Remunerative employment ", "Economic self-sufficiency" or "Informal social relationships".

Three out of five most often linked ICF categories (Body Function: "Sensation of pain"; Activities and Participation: "Walking" and "Moving around") have earlier been shown as highly predictive for the development of a joint contracture [1-3, 5-8].

Compared to the ICF components Body Structures and Activities Participation, a relatively low number of linked categories $(n=6)$ belonged to the component Environmental Factors. Three of these six categories of Environmental Factors were found frequently in our review (in $20 \%, 37 \%$, and $45 \%$ of the 60 studies analysed), indicating that at least some contextual factors are considered relevant for functioning of persons with joint contractures. Since our recent qualitative interviews draw the attention to the major role of mobility for daily life of older persons with joint contractures [25], modelling of future joint contracture outcomes should take environmental factors into account. The importance of facilitators of walking and moving, such as walking aids and creation of barrier-free buildings has been pointed out in former research dealing with joint contractures [25-27].

Our study has potential limitations. Linking concepts of outcome measures to ICF categories is not simple and straightforward. Recent linking exercises, however, have demonstrated that it is possible to examine and compare the content of measures based on the ICF framework [13].

We did not review the psychometric properties of the outcome measures identified. However, this systematic review was solely dedicated to the description of outcome measures used in recent research as the first step in the generation of an ICF standard set on joint contractures. It was not our intention to critically appraise existing assessment instruments and single outcome measures in order to decide which outcome measure should be used.

\section{Conclusion}

The revealed ICF categories remain to be validated in terms of clinical relevance and personal impact in populations affected by joint contractures. Our consecutive steps towards ICF standard set development will be reported elsewhere.

\section{Additional file}

Additional file 1: Structure of the International Classification of Functioning, Disability and Health (ICF). (DOC 67 kb)

Competing interests

The authors declare that they have no competing interests.

Authors' contributions

EG, MM, GM and GB applied for funding of the study. GB and SN retrieved the studies; GB and SN extracted the data. UF and RS conducted the statistical analysis. GB drafted the manuscript, GM supported paper drafting. UF, MM, EG, RS, SN and GM critically revised the drafts and contributed to the final writing of the paper. All authors read and approved the final manuscript.

\section{Acknowledgements}

We would like to thank the BScN students Florian Loetz and Anne Müller for their assistance with data extraction and abstract screening.

The project is funded by the German Federal Ministry of Education and Research (Grant 01GY1113A/B). The authors bear full responsibility for the content of this publication.

\section{Author details}

${ }^{1}$ Faculty of Health, School of Nursing Science, Witten/Herdecke University, Witten, Germany. ${ }^{2}$ Institute for Health and Nursing Science, Martin Luther University, Halle-Wittenberg, Germany. ${ }^{3}$ Institute for Medical Information 
Processing, Biometrics and Epidemiology, Ludwig-Maximilians-Universität München, Munich, Germany. ${ }^{4}$ German Center for Vertigo and Balance Disorders, Ludwig-Maximilians-Universität München, Munich, Germany.

\section{Received: 30 July 2015 Accepted: 1 February 2016}

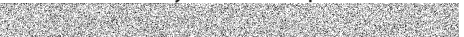

\section{References}

1. Fergusson D, Hutton B, Drodge A. The epidemiology of major joint contractures: A systematic review of the literature. Clin Orthop Relat Res. 2007:456:22-9.

2. Rabiner A, Roach KE, Spielholz NI, Judson L. Characteristics of Nursing Home Residents with Contractures. Phys Occup Ther Geriatr. 1996;13:1-10.

3. Fox P, Richardson J, Mclnnes B, Tait D, Bedard M. Effectiveness of a bed positioning program for treating older adults with knee contractures who are institutionalized. Phys Ther. 2000:80:363-72.

4. Harrington C, Carrillo H, Blank BW. Nursing, Facilities, Staffing, Residents, and Facility Deficiencies, 2001 through 2007. Department of Social and Behavioral Sciences: University of California, San Francisco; 2008. http://ualr.edu/ seniorjustice/uploads/2008/12/Nursing\%20Home\%20 Facilities,\%20Staffing,\%20Residents,\%20and\%20Facility \%20Deficiencies\%202001\%20Through\%202007. Accessed 8/2/2016.

5. Wagner LM, Capezuti E, Brush BL, Clevenger C, Boltz M, Renz S. Contractures in frail nursing home residents. Geriatr Nurs. 2008;29:259-66.

6. Resnick B. Functional performance and exercise of older adults in long-term care settings. J Gerontol Nurs. 2000;26:7-16.

7. Souren LE, Franssen EH, Reisberg B. Contractures and loss of function in patients with Alzheimer's disease. J Am Geriatr Soc. 1995;43:650-65.

8. Mollinger LA, Steffen TM. Knee flexion contractures in institutionalized elderly: prevalence, severity, stability, and related variables. Phys Ther. 1993;73:437-44

9. Gnass I, Bartoszek G, Thiesemann R, Meyer G. Joint contractures in older age. A systematic literature review. Z Gerontol Geriatr. 2010;43:147-57.

10. Offenbächer M, Sauer S, Rieß J, Müller M, Grill E, Daubner A, et al. Contractures with special reference in elderly: definition and risk factors - a systematic review with practical implications. Disabil Rehabil. 2014;36:529-38.

11. World Health Organisation (WHO). International Classification of Functioning, Disability and Health: ICF. Geneva: WHO; 2001.

12. Stier-Jarmer M, Grill E, Mueller M, Strobl R, Quittan M, Stucki G. Validation of the comprehensive ICF Core Set for patients in geriatric post-acute rehabilitation facilities. J Rehabil Med. 2011;43:113-22.

13. Selb M, Escorpizo R, Kostanjsek N, Stucki G, Ustün B, Cieza A. A guide on how to develop an international classification of functioning, disability and health core set. Eur J Phys Rehabil Med. 2014;51:105-17.

14. Müller M, Fischer U, Bartoszek G, Grill E, Meyer G. Impact of joint contractures on functioning and social participation in older individuals - development of a standard set (JointConFunctionSet): study protocol. BMC Geriatr. 2013;13:18.

15. Grill E, Ewert T, Chatterii S, Kostanjsek N, Stucki G. ICF Core Sets development for the acute hospital and early post-acute rehabilitation facilities. Disabil Rehabil. 2005;27:361-6.

16. Insall JN, Dorr LD, Scott RD, Scott WN. Rationale of the Knee Society clinical rating system. Clin Orthop Relat Res. 1989;248:13-4.

17. Scheuringer M, Grill E, Boldt C, Mittrach R, Müllner P, Stucki G. Systematic review measures and their concepts used in published studies focusing on rehabilitation in the acute hospital and in early post-acute rehabilitation facilities. Disabil Rehail. 2005;27:419-29.

18. Bellamy N. WOMAC Osteoarthritis Index User Guide. 5th ed. Brisbane: Australia; 2002.

19. Cieza A, Geyh S, Chatterji S, Kostanjsek N, Ustun B, Stucki G. ICF linking rules: an update based on lessons learned. J Rehabil Med. 2005;37:212-8.

20. Ranawat CS, Ranawar AS, Ranawat AS. Ranawat Orthopaedic Center Patient administered questionnaire - KNEE. 2010. http://www.ranawatorthopaedics. com/pdf/knee-patient-form-new.pdf. Accessed 8/2/2016.

21. Cristopoliski F, Barela JA, Leite N, Fowler NE, Rodacki AL. Stretching exercise program improves gait in the elderly. Gerontology. 2009;55:614-20.

22. Carr JH, Shepherd RB, Nordholm L, Lynne D. Investigation of a New Motor Assessment Scale for Stroke Patients. Phys Ther. 1985;65:175-80.

23. Jain S, Wasnik S, Hegde C, Mittal A. High-flexion bearing knees: impact on patellofemoral outcomes in 159 patients. J Knee Surg. 2014;27:113-7.
24. Daniilidis K, Skwara A, Skuginna A, Fischer F, Tibesku CO. Comparison ofmedium-term clinical and radiological outcome between cemented and cementless medial unicompartmental knee arthroplasty. Z Orthop Unfall. 2009;147:188-93.

25. Fischer U, Bartoszek G, Müller M, Strobl R, Meyer G, Grill E. Patients' view on health-related aspects of functioning and disability of joint contractures: a qualitative interview study based on the International Classification of Functioning, Disability and Health (ICF). Disabil Rehabil. 2014;36:2225-32.

26. Fischer U, Müller M, Strobl R, Bartoszek G, Meyer G, Grill E. Examining Functioning and Contextual Factors in Individuals with Joint Contractures from the Health Professional Perspective Using the ICF: An International InternetBased Qualitative Expert Survey. Rehabil Nurs 2014 [Epub ahead of print].

27. Bracy NL, Millstein RA, Carlson JA, Conway TL, Sallis JF, Saelens BE, et al. Is the relationship between the built environment and physical activity moderated by perceptions of crime and safety? Int J Behav Nutr Phys Act. 2014;11:24.

28. Mahoney I, Barthel W. Functional evaluation: The Barthel Index. Md State Med J. 1965:14:56-61.

29. Van der Lee JH, Beckerman H, Lankhorst GJ, Bouter LM. The responsiveness of the Action Research Arm Test and the Fugl-Meyer Assessment scale in chronic stroke patients. J Rehabil Med. 2001;33:110-3.

30. Gracies JM, Marosszeky JE, Renton R, Sandanam J, Gandevia SC, Burke D. Short-term effects of dynamic Lycra splints on upper limb in hemiplegic patients. Arch Phys Med Rehabil. 2000:81:1547-55.

31. Ware Jr JE, Sherbourne CD. The MOS 36-item short-form health survey (SF-36). Conceptual framework and item selection. Med Care. 1992;30:473-83.

32. Bohannon RW, Smith MB. Interrater reliability of modified Ashworth scale of muscle spasticity. Phys Ther. 1987;67:206-7.

33. Morrey BF, An KN, Chao EYS. Functional evaluation of the elbow. In: Morrey BF, editor. The elbow and its disorders. 2nd ed. Philadelphia: WB Saunders; 1993. p. 86-97.

34. Germann G, Harth A, Wind G, Demir E. Standardisation and validation of the German version 2.0 of the Disability of Arm, Shoulder, Hand (DASH) questionnaire. Unfallchirurg. 2003;106:13-9.

\section{Submit your next manuscript to BioMed Central and we will help you at every step:}

- We accept pre-submission inquiries

- Our selector tool helps you to find the most relevant journal

- We provide round the clock customer support

- Convenient online submission

- Thorough peer review

- Inclusion in PubMed and all major indexing services

- Maximum visibility for your research

Submit your manuscript at www.biomedcentral.com/submit 